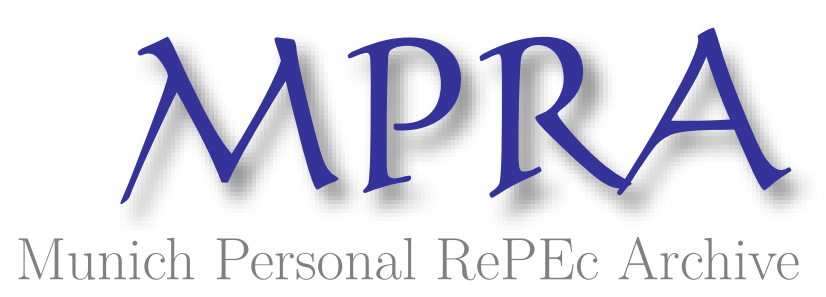

\title{
Arbitrage Opportunities, Efficiency, and the Role of Risk Preferences in the Hong Kong Property Market
}

Tsang, Chun-Kei and Wong, Wing-Keung and Horowitz, Ira

Hong Kong Baptist University, Asia University, University of Florida

17 May 2016

Online at https://mpra.ub.uni-muenchen.de/74347/

MPRA Paper No. 74347, posted 08 Oct 2016 14:15 UTC 


\title{
Arbitrage Opportunities, Efficiency, and the Role of Risk Preferences in the Hong Kong Property Market
}

\author{
Tsang, Chun-Kei \\ Department of Economics, Hong Kong Baptist University, Hong Kong \\ Wong, Wing-Keung \\ Department of Finance, Asia University, Taiwan \\ Department of Economics, Hong Kong Baptist University, Hong Kong \\ Department of Economics, Lingnan University, Hong Kong \\ Horowitz, Ira \\ Department of Information Systems and Operations Management \\ University of Florida, Warrington College of Business Administration, United States
}

\begin{abstract}
This paper aims at investigating how a prospective buyer's optimal home-size purchase can be determined by means of a stochastic-dominance (SD) analysis of historical data of Hong Kong. By means of SD analysis, the paper employs monthly property yields in Hong Kong over a 15-year period to illustrate how buyers of different risk preference may optimize their home-size purchase. Regardless of whether the buyer eschews risk, embraces risk, or indifference to it, in any adjacent pairing of five well-defined housing classes, the smaller class provides the optimal purchase. In addition, risk averters focusing on total yield would prefer to invest in the smallest and second- smallest classes than in the largest class. As the smaller class provides the optimal purchase, the smallest class affords the buyer the optimal purchase over all classes in this important housing market - at least where rental yields are of primary concern. The findings suggest that in the Hong Kong housing market, long-term investors may be better off purchasing smaller homes. For other type of investors, it depends on their risk preference. There is a very small body of empirical literature on housing investment, especially if focuses on the optimal home-size purchase.
\end{abstract}

Keywords: urban studies; stochastic dominance; risk averters, risk seekers, investors with S-shaped and reverse S-shaped utilities, housing investment

\section{JEL Classification: C14, G14, R31}

Acknowledgments: The authors would like to thank the Editor, Professor Robert Brooks and two anonymous referees for their constructive comments and suggestions, which help us to clarify more precisely the results and lead to the substantial improvement of an early manuscript. Also, the authors would like to thank Jun Jie Gao, Xiao Long Li and Wayne Archer for their helpful comments on an earlier draft. The second author would also like to thank Robert B. Miller and Howard E. Thompson for their ongoing counseling and encouragement. This research has been partially supported by grants from Hong Kong Baptist University, Asia University, Lingnan University, Hong Kong, and the Research Grants Council of Hong Kong. We take sole responsibility for the final product. 


\section{Introduction}

The decision to purchase a particular home involves a variety of considerations that run the gamut from the choice of an affordable lifestyle at one end of the spectrum to a "flippable" investment opportunity at the other, to some combination of the two. We venture to suggest that few prospective home buyers can afford to overlook the possibility that they might be impelled to sell the home in the future. The focus of the present paper is on the determination of the optimal home-size purchase, ceteris paribus, and the stochastic-dominance (SD) approach to the resolution of the problem.

A case in point is the Hong Kong housing market, which Qiao and Wong (2015) previously examined. Applying an SD test to housing prices in Hong Kong, they concluded that smaller houses are the better investment choice. That result, however, only applies to risk-averse investors, as they mainly found a higher-order SD relationship. Moreover, prices and rents are inseparable when considering housing investments, especially for such long-term investors as pension funds, REITs or even individual owners for whom both prices and rents need to be viewed in tandem. Thus, we propose the use of housing yield to tackle this issue anew.

Qiao and Wong 's results (2015) imply that the Hong Kong property market is efficient and does not provide an opportunity for arbitrage, when one considers price appreciation or total yield. We reexamine the issue by looking into the rental yield in that market. We also consider whether the market affords arbitrage opportunities and, if so, how one could exploit them. Finally, our results are applicable not just to risk-averse investors with strictly concave risk-preference functions, but to risk-neutral investors, risk takers with strictly convex risk-preference functions, and even to those with S-shaped or reverse S-shaped risk-preference functions - that is, to investors that might exhibit risk-taking behavior at one level of wealth and risk-avoiding behavior at another, provided only that they prefer greater yield to lesser yield. 
Within this setting we apply the SD approach to the analysis of uncertain prospects, to compare the performance of five classes of housing for long-term investors, regardless of the shapes of their risk-preference functions. As a result of so doing, the paper makes six distinctive contributions and goes well beyond Qiao and Wong's earlier (2015) work.

First, and most critically, we show that regardless of whether a prospective home buyer eschews risk, embraces risk, or is indifferent to it, or whether that attitude changes when the buyer's wealth or the property's yield changes, in any adjacent pairing of Hong Kong housing classes, the smaller class provides the optimal purchase. Thus, the smallest class affords the buyer the optimal expected wealth from rental yield over all classes, and for buyers focusing on total yield, it is preferred over the largest class.

Second, there is an arbitrage opportunity in the rental yield of the Hong Kong property market. For example, if one would like to buy a large house for one's own use, one could consider the equally-costly alternative of purchasing smaller houses for rental purposes, with a portion of the resulting rents providing the funds for renting one's own, larger home. Assuredly, there may be tax considerations, but these are easily dealt with by, for example, setting up a company to take care of the various transactions.

Third, we show that the Hong Kong property market is not efficient in term of rental yield, and fourth we demonstrate the efficacy of the SD rule in the analysis of any real-estate market and for any investor that prefers more yield to less yield, regardless of that investor's attitude towards risk. Fifth, we believe our paper to be the first demonstration of first-order SD over an extended period of time.

Last, but by no means least, we apply a recently-developed powerful SD test to examine total yield from a housing purchase. While Qiao and Wong (2015) found many second-order SD relationships among the different classes of investment, we find only two second-order SD and only two third-order SD relationships for all different property classes. That difference might be attributable to our more powerful SD test.

The paper is organized as follows. The next section briefly introduces the housing 
market in Hong Kong and, reviews the most relevant literature so as to motivate the analysis to follow. In Section 3 we describe the data and the SD approach. The following two sections present our empirical results, after which we draw three related inferences. The final section offers our conclusions.

\section{Literature review}

\subsection{The Hong Kong housing market}

On July 1, 1997, Hong Kong became a Special Administrative Region (SAR) of the People's Republic of China, to be governed under a policy of "one country, two systems." As such, the territory's economy in general and its housing market in particular, is subject to the vicissitudes of both the mainland economy and the other Asian economies. Yet it remains one of the most important, vibrant, and popular housing markets in the world. The Association of Foreign Investors in Real Estate listed Hong Kong as one of the top-10 cities in which to invest in housing in 2012. ${ }^{1}$ Hong Kong was also listed as one of the world's 10 most important cities over the past 10 years and in the top five of the world's largest financial centers, as well as the "global City" in $2013{ }^{2}$

Hong Kong is also renowned for its population density, with seven million people occupying less than 300 square kilometers of built-up areas. Hong Kong's residential density is also one of the world's highest, with approximately seven thousand people living in each square kilometer, which is higher than Tokyo and London. As a result, Hong Kong is one of the most expensive housing markets in the world in terms of prices and rents. The market is also is one of the most volatile (Xiao and Liu, 2010). In 2014, there were 1.14 million private housing units in Hong Kong, and the value of registered agreements for the sale of private housing units reached HK\$ 257 billion. Further, the

\footnotetext{
12012 Foreign Investment Survey, Association of Foreign Investors in Real Estate, http://afire.org/annual-foreign-investment-survey

2 The Wealth Report, Knight Frank Research. http://www.thewealthreport.net
} 
vacancy rate of private housing units reached a 17-year low of 3.8 in 2014, which peaked at $6.8 \%$ after the Asian Financial Crisis in $1997 .^{3}$

Since in the main previous studies of property markets have focused on well-developed housing markets such as those of the US and the Euro Region, while tending to neglect the emerging markets, our focus on Hong Kong provides a different perspective and extends the existing literature to Asia.

\subsection{Housing investment}

Purchasing a house plays an important role in both consumption and investment decisions (Henderson and Ioannides, 1987). Economists have mainly focused on the consumption aspects of this process, while academics such as Dusansky and Koç (2007), Hiebert and Sydow (2011), Paciorek and Sinai (2012), and Chen et al. (2012) have shown that one should not ignore the investment aspects of the purchasing process, since most buyers consider housing to be a "lifetime" investment.

Some authors advocate buying larger houses for investment portfolios. For example, Ziering and McIntosh (2000) find that housing size is an important factor in determining the risk and return of housing, and conclude that the largest class of housing provides investors with the highest return and also the greatest volatility. Flavin and Nakagawa (2002) and Flavin and Yamishita (2008), however, suggest that investing in larger houses does not necessarily reduce risk. By way of explanation, Krainer (2001), McMillen (2008), and Ihlanfeldt and Mayock (2012) point out that a spectrum of prices, rather than a single price, exist in the housing market. Still further, Zimmer (2012) suggests that huge housing portfolios are a source of instability in the market.

While the "size effect" in housing portfolios has been adequately explored, only a few studies have attempted to link size directly to housing investment. For example,

\footnotetext{
3 Census and Statistics Department- The Government of the Hong Kong Special Administrative Region, http://www.censtatd.gov.hk
} 
Kallberg et al. (1996) show that since smaller-property values have lower correlations with stocks and bonds, they offer particularly impactful diversification benefits for investment portfolios with high-return aspirations. By contrast, Graff and Young (1996), Lin and Liu (2008), and Zimmer (2012) suggest that the link between housing size and housing performance needs to be further investigated, with a particular need for accurate measurement of the return and risk for different house sizes.

Turnbull et al. (2006) directly broach the optimal house-size question, looking at the sales prices of houses in a Louisiana parish over an almost six-year period. They draw their inferences from the parameter estimates of a two-stage least-squares linear regression that includes, among its independent variables, living area. Their results imply that the answer to the question, even for that parish, which they acknowledge might not apply elsewhere, is "it depends." That is, for example, "smaller houses in a neighborhood of larger houses sell at a premium relative to small houses in small-house neighborhoods" (Turnbull et al., 2006, p. 453).

There are different approaches to analyzing housing returns and risk. Studies such as Topel and Rosen (1988), Archer et al. (1996), Fuerst et al. (2015) and Ciarlone (2015) suggest that housing returns can be expressed in terms of a set of macroeconomic variables. Harter-Dreiman (2004) studies the housing market by forming a link between housing prices and economic cycles. Cannon et al. (2006) explain housing returns by volatility, price level and stock-market risk, whereas Ghent and Owyang (2010) investigate supply and demand to explain movements in the housing market. Qiao and Wong (2015) examine housing prices by adopting an SD test on different housing sizes in Hong Kong, but do not find any superior housing size for all investors.

Alternatively, there are suggestions that the return to housing investment should be viewed in terms of yields. For example, Campbell and Shiller (1988) and Clayton (1996) provide strong support for the theory that the yield in the housing market is similar to the dividend-price ratio in the financial market. Leamer (2002) states that housing prices 
should reflect the present value of future rent, and further that investors should use the same calculations when purchasing a house as they do when purchasing a stock. Dreman (1982) and Gallin (2008) show the importance of using yields in housing investment, because yields can be a good indicator of housing investment under the concept that rent is a prime element of the value of housing. Nevertheless, Addae-Dapaah et al. (2010) find that the contrary strategy also works in real-estate investment, implying that high-yield housing could precede low-yield housing. And Ayuso and Restoy (2006) suggest that housing yields possess the merit of circumventing the specification of the user cost and/or of the market price of housing services.

To conclude, using yield could finesse the problems arising from dealing with both prices and rent. In what follows we therefore treat housing investment as a type of annuity and consider yields in the analysis.

\subsection{Stochastic dominance}

SD theory, which originated with Hadar and Russell (1969) and Hanoch and Levy (1969), is one of the most powerful instruments with which to compare investment prospects under uncertainty, and the Hong Kong real-estate market, particularly during our 15-yearsample period that extends from 1999 through 2013, is an exemplar of such. The period is an especially propitious one for study, since (1) it marks the beginning of the territory's recovery from the almost two-year Asian financial crisis that began in July 1997, and (2) it spans the global financial crisis and economic meltdown that began in mid-September 2008. The instrument's power derives from the fact that different SD relationships correspond to different sets of risk preferences.

The historical focus of the investment decision-making process under uncertainty has been on the risk-averse decision maker. It has long been recognized, however, that while this may be a mathematically convenient approach, it is far too narrow (Markowitz, 1952; 
Levy and Wiener, 1998; Levy and Levy, 2002; Levy and Levy, 2004; Wong and Chan, 2008). For example, our main finding is that the smaller house dominates the bigger house in the sense of first-order SD (FSD) for risk averters. This dominance, however, implies FSD for risk takers as well as for investors with S-shaped and reverse S-shaped risk-preference functions (Sriboonchitta et al., 2009). In related veins, Hoang et al. (2015) apply both SD for risk-averse and risk-taking investors to study their preferences in gold diversification, because they only find a second-order SD but not a first-order SD relationship for risk averters and risk takers. Similarly, Fong et al. (2008) employ SD for investors with S-shaped and reverse S-shaped risk-preference functions to analyze their preferences between Internet stocks and traditional stocks, because they only find a second-order SD but not a first-order SD relationship for investors with S-shaped and reverse S-shaped risk-preference functions.

Early theoretical studies such as Hanoch and Levy (1969) linked SD theory to the selection rule for risk avoiders under various constraints on their risk-preference functions. SD theory has also been extended to other types of investors. As will be seen, our results satisfy first-order SD for risk avoiders, and the latter implies first-order SD for risk takers as well.

Levy and Sarnat (1970), Porter (1973) and Joy and Porter (1974) applied the SD rule empirically but did not discuss the testing procedure. Some significant SD tests have recently been developed. For example, Barrett and Donald (2003) exploit a Kolmogorov-Smirnov-type test and Linton et al. (2005) further relax the i.i.d. assumption. In addition, Anderson (1996) and Davidson and Duclos (2000) develop SD tests that examine the underlying distributions at a finite number of grid points. Armed with these powerful tests, the SD approach becomes widely applicable. Most critically, and as detailed in Section 3.2, FSD of one investment prospect over another implies that regardless of one's risk preferences and the shape of one's risk-preference function, the dominant prospect is the preferred investment. We apply the Davidson and Duclos (2000) 
DD test to make this determination.

\section{The data and methodology}

\subsection{The data}

We consider monthly property-market rental yields in private domestic units of five different housing classes (saleable area) from January 1999 to December 2013. The data are obtained from the Rating and Valuation Department of the Hong Kong SAR. The monthly rental yields for each class are calculated by dividing the average rent within that class by the average sale price for houses in that class, in that month. These average rents and sales prices are government estimates that are based on that month's transactions. Thus the data provide a broad indication of market yields and trends.

Total yield is defined as monthly rental yield plus the monthly price return. Private domestic units are defined as independent dwellings with separate cooking facilities and bathrooms (and/or lavatories). They are sub-divided into five classes by reference to floor area: Class A - saleable area less than $40 \mathrm{~m}^{2}$; Class B - saleable area of $40 \mathrm{~m}^{2}$ to $69.9 \mathrm{~m}^{2}$; Class C - saleable area of $70 \mathrm{~m}^{2}$ to $99.9 \mathrm{~m}^{2}$; Class D - saleable area of $100 \mathrm{~m}^{2}$ to $159.9 \mathrm{~m}^{2}$; and Class E - saleable area of $160 \mathrm{~m}^{2}$ or above.

The data comprise private second-hand sales, and exclude public-sector development housing, and primary sales. The descriptive statistics for rental yields are shown in Table 1. The yield data exclude fees and taxes, as Hong Kong is a low-tax region, one in which property tax is charged on a proportional basis at an effective rate of around $12 \%$ on rental income. This helps to make Hong Kong an ideal case to study, since the results are not impacted by high or non-proportional transaction costs.

Indeed, the dataset has a number of advantages. First, it provides official monthly data for both rents and prices for all five classes. Second, each yield is calculated based 
on all the rental and sale transactions in each month. Third, since Hong Kong is a city the data reduce the problems that arise from differences between different areas, thus ameliorating the problems of age, location, and other housing attributes.

The above partition is suggested by the Rating and Valuation Department of the Hong Kong SAR which reports the data used herein, under this partition. While, for example, a $41 \mathrm{sq} \mathrm{m}$ apartment on a low floor may not perform more poorly than a $39.9 \mathrm{sq}$ $\mathrm{m}$ apartment on a high floor, we do not compare the rental yield of a $41 \mathrm{sq} \mathrm{m}$ apartment on a low floor with that of a 39.9 sq m apartment on a high floor. Rather, we compare, say, all the data of Class B with saleable area of $40 \mathrm{~m}^{2}$ to $69.9 \mathrm{~m}^{2}$ with data of Class C with saleable area of $70 \mathrm{~m}^{2}$ to $99.9 \mathrm{~m}^{2}$. These are almost equivalent, as we compare the mean rental yield of all the data of Class B with saleable area of $40 \mathrm{~m}^{2}$ to $69.9 \mathrm{~m}^{2}$ with that of Class C with saleable area of $70 \mathrm{~m}^{2}$ to $99.9 \mathrm{~m}^{2}$ for all properties in the classes, including both high-floor and low- floor properties. In addition, the data include properties of various ages, building heights, floor levels and heights, proximity to metro stations, schools, and malls. Factors such as scenic views and even winter sun aspects might have a significant influence on investment performance. The data include new and existing housing. Thus, the conclusions drawn from our analysis are the general result for all characteristics of the properties. Further study could include comparison of different sizes of properties under their particular characteristics.

\subsection{Methodology}

\section{Stochastic-dominance theory}

Let $F$ and $G$ be the cumulative distribution functions (CDFs), and $f$ and $g$ be the corresponding probability density functions (PDFs) of two investments, $Y$ and $\mathrm{Z}$, respectively, with common support of $[a, b]$, where $a<b$, and respective means of $\mu_{y}$ and 
$\mu_{z}$

Define

$H_{0}=h$ and $H_{j}(x)=\int_{a}^{x} H_{j-1}(t) d t$ for $h=f, g, H=F, G$, and $j=1,2,3$.

The most frequently-used SD rule is compatible with three broadly-defined risk-avoiders' risk-preference functions: notably, first-order, second-order, and third-order SD, denoted FSD, SSD, and TSD, respectively. The SD rules are: $Y$ dominates $Z$ by FSD, denoted $Y \succ_{1} Z$, if and only if $F_{1}(x) \leq G_{1}(x) ; Y$ dominates $Z$ by SSD, denoted $Y \succ_{2} Z$, if and only if $F_{2}(x) \leq G_{2}(x)$; and finally $Y$ dominates $Z$ by TSD, denoted $Y \succ_{3} Z$, if and only if $F_{3}(x) \leq G_{3}(x)$ for all possible returns $x, \mu_{y} \geq \mu_{z}$, and a strict inequality for a non-empty interval of $x$.

Investigating the SD relationship among different investments is equivalent to examining the choice of investments by expected-utility maximization. SD implies that holding the dominant asset always gives a higher expected utility than holding the dominated assets. Under FSD, investors will exhibit non-satiation (more is preferred to less); under SSD, investors will have the additional characteristic of risk aversion; and under TSD they also have decreasing absolute risk aversion. Since a hierarchical relationship exists in SD (Levy 1992), which means FSD implies SSD and TSD, only the lowest dominance order of SD is reported.

\section{The Davidson and Duclos test}

Let $\left\{\left(y_{i}, z_{i}\right)\right\}$ be pairs of observations drawn from the random variables $Y$ and $\mathrm{Z}$, with distribution functions $F(x)$ and $G(x)$, respectively, for market yields of private domestic units from two different classes. The integrals $F_{j}(x)$ and $G_{j}(x)$ for $F$ and $G$ are defined in (1) for $j=1,2,3$. For a grid of pre-selected points $x_{1}, x_{2} \ldots x_{k}$, the $j^{\text {th }}$-order DD test statistic, $T_{j}(x)(j=1,2$ and 3$)$, is: 


$$
T_{j}(x)=\frac{\widehat{F}_{j}(x)-\widehat{G}_{j}(x)}{\sqrt{\widehat{V}_{j}(x)}},
$$

where $\quad \widehat{V}_{j}(x)=\widehat{V}_{F, j}(x)+\widehat{V}_{G, j}(x)-2 \widehat{V}_{F G, j}(x)$,

$$
\begin{gathered}
\widehat{H}_{j}(x)=\frac{1}{N(j-1) !} \sum_{i=1}^{N}\left(x-h_{i}\right)_{+}^{j-1} \\
\widehat{V}_{H, j}(x)=\frac{1}{N}\left[\frac{1}{N((j-1) !)^{2}} \sum_{i=1}^{N}\left(x-h_{i}\right)_{+}^{2(j-1)}-\widehat{H}_{j}(x)^{2}\right], H=F, G, h=f, g, \\
\widehat{V}_{F G, j}(x)=\frac{1}{N}\left[\frac{1}{N((j-1) !)^{2}} \sum_{i=1}^{N}\left(x-f_{i}\right)_{+}^{j-1}\left(x-g_{i}\right)_{+}^{j-1}-\widehat{F}_{j}(x) \widehat{G}_{j}(x)\right] .
\end{gathered}
$$

It is not possible to test the null hypothesis for the full support of distributions, empirically. Thus, Bishop et al. (1992) propose testing the null hypothesis for a pre-designated finite number of values of $x$. The following four hypotheses are tested:

$H_{0}: F_{j}\left(x_{i}\right)=G_{j}\left(x_{i}\right)$, for all $x_{i}, i=1,2, \ldots, k$;

$H_{A}: F_{j}\left(x_{i}\right) \neq G_{j}\left(x_{i}\right)$, for some $x_{i}$;

$H_{A 1}: F_{j}\left(x_{i}\right) \leq G_{j}\left(x_{i}\right)$, for all $x_{i}, F_{j}\left(x_{i}\right)<G_{j}\left(x_{i}\right)$ for some $x_{i}$;

$H_{A 2}: F_{j}\left(x_{i}\right) \geq G_{j}\left(x_{i}\right)$, for all $x_{i}, F_{j}\left(x_{i}\right)>G_{j}\left(x_{i}\right)$ for some $x_{i}$.

To conduct the DD test, the $T_{j}(x)$ at each grid point is computed and the null hypothesis, $H_{0}$, is rejected if $T_{j}(x)$ is significant at any grid point. Accepting either $H_{0}$ or $H_{A}$ implies that there is no SD relationship between $F$ and $G$. If $H_{A 1}\left(H_{A 2}\right)$ of order one is accepted, $F(G)$ dominates $G(F)$ in FSD. If $H_{A 1}$ or $H_{A 2}$ is accepted for orders two or three, SD exists in the second or third order. In this situation, switching from the dominated asset to the dominant one will only increase risk-avoiders' expected utilities but not their expected wealth (Falk and Levy, 1989).

The DD test compares the distributions at a finite number of grid points. In order to make the comparisons comprehensive, we make 10 major partitions with 10 minor partitions within any two consecutive major partitions in each comparison. Bai et al. (2015) improve the DD test by deriving the limiting process of the DD statistic $T_{j}(x)$, and hence the DD test can be performed by $\max _{x}\left|T_{j}(x)\right|$ to take care of the dependency of the partitions. Their procedure is employed in carrying out the test. 
Qiao and Wong (2015) apply the SD tests developed by Davidson and Duclos (2000) and Linton et al. (LWM, 2005). We apply the SD test developed by Bai et al. (2015). The SD test developed by Davidson and Duclos (2000) is powerful but benefits from the ministrations of Bai et al. (2015) who derive the limiting process of SD tests for both risk averters and risk takers, regardless of whether the underlying processes are dependent or independent. They overcome the problem of dependence among the chosen grid points and propose a bootstrap method to obtain a critical value that is closer to the true critical value.

We have also conducted our analysis by using the SD test developed by Linton et al. (2005). Because the conclusions drawn from the latter test are the same as those of the Bai et al. (2015) SD test, we do not report those results. The beauty of applying the SD tests to conduct our analysis is that in contrast to many other statistical methods, we do not have to impose any assumptions, including the ceteris paribus assumption.

We only discuss the SD tests for risk averters developed by Davidson and Duclos (2000) and Bai et al. (2015), but not those developed for risk takers (Wong, 2007; Bai et al., 2015) or those for investors with S-shaped and reverse S-shaped risk-preference functions, because (a) we mainly discuss our first-order SD (FSD) relationship-finding for rental yield, and (b) if yield $\mathrm{X}$ dominates yield $\mathrm{Y}$ in the sense of the FSD for risk averters, then it implies that $\mathrm{X}$ dominates $\mathrm{Y}$ in the sense of the FSD for risk takers ( $\mathrm{Li}$ and Wong, 1999), and $\mathrm{X}$ dominates $\mathrm{Y}$ in the sense of the FSD for investors with S-shaped and reverse S-shaped risk-perference functions (Wong and Chan, 2008). We discuss this issue further in the next two sections.

\section{The empirical results: Rental yield}

\subsection{The visual evidence}


Figure 1 provides the time-series plots of the rental yields for all five classes over the entire period of study, revealing that the yield of Class A rests at the top, with that of Class B following, and so on down the line until we get to the yield of Class $\mathrm{E}$ at the bottom, thus suggesting that over the entire period the smallest house provides the highest yield and the largest house the smallest yield.

Figure 2 shows the density plots of rental yields from all five classes. The plots provoke an initial impression that FSD could exist among all yields of different classes, because some PDFs are on the right-hand side of some others. The plots show that some PDFs have higher yields. For example, Class E ranges from $0.18 \%$ to $0.45 \%$, while Class A ranges from $0.26 \%$ to $0.54 \%$.

As an initial indicator of whether there might be any dominance relationships, in Figure 3 we plot the CDFs of the rental yields from the five different classes. The figure shows a provocative phenomenon: namely, the CDF of Class A is at the bottom, while that of Class B is on top of Class A, and so on until the top line is the CDF of Class E. The class on the bottom is the most preferred because, at any point, the value of its CDF is the smallest, implying that it has the least probability of gaining less (or, equivalently, the least probability of losing more) up to this point, and thus, it has the highest probability of gaining more. In this sense, Figure 3 shows that Class A dominates Class B, which dominates Class C, Class D, and then Class E.

\subsection{The Davidson and Duclos test}

The dominance relationship exhibited in Figure 3 only gives us some ideas as to the dominance relationship among different classes, but it does not properly test the relationship itself. To formally conduct the test, we employ the DD test statistic to make pairwise comparisons of the five classes. We compute the values of the statistic over a grid of 100 comprising the 10 major, and 10 minor, partitions on the monthly rental yields. 
Table 2 records the percentage of significant statistics, based on the simulated critical value suggested by Bai et al. (2011). The DD statistics, $T_{1}, T_{2}$, and $T_{3}$, are negative in the entire range of the yield distribution, most of the range is significantly negative, and no portion of $T_{j}$ is positive.

For an improved perspective of the DD test comparison, we plot the test statistics and the corresponding CDFs for each pair of yields from different classes, although only the plots of Classes A and E are displayed in Figure 4, since the plots of all other pairs of distributions are similar to those displayed in the figure. In tandem, the plot of the test statistics and the corresponding CDFs implies that Class A dominates Class E in first, second, and third order, below, since $T_{1}, T_{2}$, and $T_{3}$ are significantly negative for $94 \%$, $97 \%$, and $99 \%$ of the distribution, respectively. Similarly, Class B dominates Class E in first, second, and third order, as $T_{1}, T_{2}$, and $T_{3}$ are significantly negative for $89 \%, 99 \%$, and $99 \%$ of the distribution, respectively. The results from Table 3 show FSD among all yields. That is, Class A dominates Classes B, C, D, and E; Class B dominates Classes C, D, and E; Class C dominates Classes D and E; and Class D dominates Class E, in the sense of FSD. We summarize the SD results in Table 3.

The fact that the rental yield from Class E dominates that from Class D in the sense of the FSD for risk averters further implies that the yield from Class E dominates that from Class D in the sense of the FSD for risk takers, too (Li and Wong, 1999). Moreover, that from Class $\mathrm{E}$ dominates that from Class D in the sense of the FSD for investors with S-shaped and reverse S-shaped risk-preference functions (Wong and Chan, 2008) or indeed for any investor that prefers higher to lesser yields. Thus, all investors whose focus is on rental yields can increase their expected utility (in the von Neumann-Morgenstern sense) as well as their expected wealth, by shifting their investments from Class E to Class D, from Class D to Class C, from Class C to Class B, and from Class B to Class A. 


\section{The empirical results: Total yield}

Some investors may not be interested solely in getting high rental yields. Rather, their interest could be focused on the total yield of their properties. The latter is defined as the rental yield plus the price return or the price-appreciation rate. Thus, in this section we investigate the performance of the monthly total yields for the five different classes of private domestic units, to complement the findings for rental yields alone.

To help analyze the performance of the monthly total yields, and comparable to Figures 1-3 on rental yields, Figures 5-7 show, respectively, the time-series plots of total yields, the PDF plot of total yields, and the CDF plot of total yields, from all classes over the period of study.

Focusing first on Figure 5, the time-series plots of total yields for the five housing classes, unlike the pattern depicted in Figure 1 for rental yields alone, do not reveal any apparent dominance from any particular class. But the CDF plots of all the total yields, shown in Figure 6, reveal the dominance of the smaller houses over the largest house. Inasmuch as in tandem the PDF and CDF plots of total yields do not immediately presage the dominance of any one housing size class, we conjecture that FSD is not present in regard to total yields, and confirm this conjecture from the DD results, which are displayed in Table 5.

Specifically, none of the FSD tests is significant for any pairs other than classes B and E. For those two classes, only one percent are significantly greater than zero, while another one percent are significantly less than zero. Nonetheless, there might well be higher-order SD among the different classes. Thus, we move on to examine the higher-order DD tests, the details of which were presented in Section 3.2.

The second-order DD (SSD) test shows that only Class A SSD-dominates Class E, in that 30 percent of the SSD DD tests are significantly less than zero, and Class B marginally SSD-dominates Class E, in that four percent of the SSD tests are significantly 
less than zero. Further, the third-order test (TSD) shows that Class A TSD-dominates Classes $\mathrm{C}$ and $\mathrm{E}$, and marginally TSD-dominates Class D, in that only one percent of the TSD DD tests are significantly less than zero, while Class B TSD-dominates Class E. Since a hierarchical relationship exists in SD (Levy, 1992), Table 6 only reports the lowest dominance order of SD. Some such as Fong et al. (2005) and Qiao et al. (2014), however, evince a disdain for "almost-SD" results (Leshno and Levy, 2002; Guo et al. 2014) and do not consider that there is an SD relationship between the assets if only a small number, say five percent, of the SD tests are significant. We refer to such as a marginal SD relationship. Based on this standard, as shown in Table 6 we determine that Class B marginally SSD-dominates Class E and strongly TSD-dominates Class E

\section{Three additional inferences}

\subsection{Arbitrage opportunities}

Jarrow (1986) shows that under certain regularity conditions investment $Y$ dominates investment $Z$ in FSD if and only if there is an arbitrage opportunity between $Y$ and $Z$, and that non-satiated investors can increase their wealth by shifting investments from $Y$ to $Z$. Arbitrage opportunities, however, may not exist even in the presence of FSD (Wong et al., 2008). Nonetheless, investors can increase their expected wealth and expected utility by shifting their holdings from the dominated asset to the dominant one. Thus, FSD is a necessary but not sufficient condition for the existence of an arbitrage opportunity.

We have established that the smallest class FSD-dominates the other classes in regard to rental yields. But does this imply that there is an arbitrage opportunity? The answer is in the negative, because only the rental yield of the smallest class, and not the total yield, FSD-dominates those of the other classes. The total yield of the smallest class only SSDor TSD-dominates those of the other classes, not FSD. Thus, if investors shift their housing investments from the other classes of housing to the smallest housing class, they 
could only increase their rental yield, not the total yield. In this sense, there is no arbitrage opportunity in the Hong Kong housing market.

\subsection{Market efficiency}

If one is able to earn an abnormal return, the market is considered inefficient. Market efficiency can be examined by the SD rule as follows. When non-satiated investors can increase their expected wealth by switching their choice of housing purchase, this implies an inefficient market (Falk and Levy, 1989).Thus, market efficiency can be rejected if FSD exists. Having established that the smallest class FSD-dominates the other classes in rental yields, does this finding imply that the housing market in Hong Kong is not efficient? Once again our answer is in the negative, and again because only the rental yield of the smallest class FSD-dominates those of the other classes, but not the total yield. The total yield of the smallest class only SSD-dominates or TSD-dominates those of the other classes. There is no first-order domination. Thus, if investors shift their housing investments from the other classes of housing to the smallest housing class, they could only increase their rental yield, not the total yield. In this sense, the market-efficiency hypothesis cannot be rejected for the Hong Kong housing market.

\subsection{Housing consumption}

Our focus has been primarily on the investment aspect of housing. Housing, however, serves as both consumption and investment (Henderson and Ioannides, 1987). In general, the consumption value of housing can be separated into two parts: use value, or the utility derived from living in the home, and ownership value or the utility derived from ownership of the asset that the home represents. There are two ways to enjoy the use value: one is buying a house, and the other is renting a house. Under this condition, we 
extend our study to housing consumption.

By renting a house and financing it with the rent collected from the small leased house, one can capture the use value of one's preferred house, at the minimum cost. In this sense, our findings suggest that buying a small house is still the best way to fulfill one's accommodation needs and at the same time to maximize one's rental return - at least in Hong Kong.

As to ownership value, since some individuals may prefer to own big houses not only for their market value but also for status and other reasons, it is nearly impossible to measure ownership value and compare it for different houses and different individuals.

\section{Conclusions}

Should one purchase a larger home or a smaller home? We answer that question by treating housing as a long-term investment that provides a type of annuity. This is important for such diverse long-term investors as pension funds, REITs or even individual owners that seek a higher return on their investments. We take advantage of the stochastic-dominance rule to compare the rental yields of different housing classes in Hong Kong to demonstrate the efficacy of the proffered procedure. While the results are in and of themselves of interest, insofar as the Hong Kong housing market is a major component of world investment portfolios, more critically we provide a template for applying the stochastic-dominance approach to other real-estate markets where the results will not necessarily mirror those of Hong Kong.

When we apply the rule in Hong Kong, however, we find that the smallest housing class demonstrates first-order dominance over all other classes in term of rental yields, which implies that by investing in the smallest class of housing, regardless of the shape of one's risk-preference function and attitude towards risk, investors can maximize their expected utility and expected wealth from rentals. 
When total yields are taken into consideration, however, we do not find any first-order dominance among all the five classes. In this sense, investors shifting their investment from one class of house to another in Hong Kong cannot obtain a higher total yield.

Finally, "Should one purchase a larger home or a smaller home?" Our answer is clear: in the Hong Kong housing market long-term investors are better off purchasing smaller homes; for others, it depends. 


\section{References}

Addae-Dapaah K, Webb JR, Ho KH and Tan YF (2010). Industrial real estate investment: Does the contrarian strategy work? Journal of Real Estate Finance and Economics 41(2):193-227.

Anderson G (1996). Nonparametric tests of stochastic dominance in income distributions. Econometrica 64(5): 1183-1193.

Archer WR, Gatzlaff DH and Ling DC (1996). Measuring the importance of location in house price appreciation. Journal of Urban Economics 40(3):334-353.

Ayuso J and Restoy F (2006). House prices and rents: An equilibrium asset pricing approach. Journal of Empirical Finance 13(3): 371-388.

Bai ZD, Li H, Liu HX and Wong WK (2011). Test statistics for prospect and Markowitz stochastic dominances with applications. Econometrics Journal 14(2): 278-303.

Bai ZD, Li H, McAleer M and Wong WK (2015). Stochastic dominance statistics for risk averters and risk seekers: An analysis of stock preferences for USA and China. Quantitative Finance 15(5): 889-900.

Barrett G and Donald S (2003). Consistent tests for stochastic dominance. Econometrica, 71(1): 71-104.

Bishop JA, Formly JP and Thistle PD (1992). Convergence of the south and non-South income distributions. 1969-1979. American Economic Review 82(1): 262-272.

Campbell JY and Shiller RJ (1988). Stock prices, earnings, and expected dividends. Journal of Finance 43(3): 661-676.

Cannon S, Miller NG and Pandher GS (2006). Risk and return in the U.S. housing market: A cross-sectional asset-pricing approach. Real Estate Economics 34(4): $519-552$.

Chen M, Chang C, Yang C and Hsieh B (2012). Investment demand and housing prices in an emerging economy. Journal of Real Estate Research 34(3), 345-373. 
Ciarlone A (2015) House price cycles in emerging economies. Studies in Economics and Finance 32(1): $17-52$.

Clayton J (1996). Rational expectations, market fundamentals and housing price volatility. Real Estate Economics 24(4): 441-470.

Davidson R and Duclos JY (2000). Statistical inference for stochastic dominance and or the measurement of poverty and inequality. Econometrica 68(6): 1435-1464.

Dreman D. (1982). The New Contrarian Investment Strategy. Random House: New York.

Dusansky R and Koç C (2007). The capital gains effect in the demand for housing. Journal of Urban Economics 61(2): 287-298.

Falk H and Levy H (1989). Market reaction to quarterly earnings' announcements: A stochastic-dominance based test of market efficiency. Management Science 35(4): 425-446.

Flavin M and Nakagawa S (2008). A model of housing in the presence of adjustment costs: A structural interpretation of habit persistence. American Economic Review 98(1): 474-495.

Flavin M and Yamashita T (2002). Owner-occupied housing and the composition of the household portfolio over the life cycle. American Economic Review 92(1): 345-362.

Fong WM, Lean HH, Wong, WK (2008). Stochastic Dominance and Behavior towards Risk: The Market for Internet Stocks", Journal of Economic Behavior and Organization 68(1): 194-208.

Fong WM, Wong WK and Lean HH (2005). International momentum strategies: a stochastic dominance approach. Journal of Financial Markets 8(1): 89-109.

Fuerst F, McAllister P and Sivitanides P (2015) Flight to quality?: An investigation of changing price spreads in commercial real estate markets. Studies in Economics and Finance 32(1): 2-16.

Gallin J. (2008). The long-run relationship between house prices and rents. Real Estate 
Economics 36(4): 635-658.

Ghent AC and Owyang MT (2010). Is housing the business cycle? Evidence from US cities. Journal of Urban Economics 67(3): 336-351.

Graff RA and Young MS (1996). Real estate correlations: Real-world limitations on relationships inferred from NCREIF data. Journal of Real Estate Finance and Economics 13(2): 121-142.

Guo X, Post T, Wong WK and Zhu LX (2014). Moment conditions for almost stochastic dominance. Economics Letters 124(2): 163-167.

Hadar J and Russell WR (1969). Rules for ordering uncertain prospects. American Economic Review 59(1): 25-34.

Hanoch G and Levy H (1969). The efficiency analysis of choices involving risk. Review of Economic Studies 36(3): 335-346.

Harter-Dreiman M (2004). Drawing inferences about housing supply elasticity from house price responses to income shocks. Journal of Urban Economics 55(2): 316-337.

Henderson JV and Ioannides Y (1987). Owner occupancy: Consumption vs. investment demand. Journal of Urban Economics 21(2): 228-241.

Hiebert P and Sydow M (2011). What drives returns to Euro area housing? Evidence from a dynamic dividend-discount model. Journal of Urban Economics 70(2): $88-98$.

Hoang THV, Wong WK and Zhu ZZ (2015). Is gold different for risk-averse and riskseeking investors? An empirical analysis of the Shanghai Gold Exchange. Economic Modelling 50(C): 200-211.

Ihlanfeldt K and Mayock T (2012). Information, search, and house prices: revisited. Journal of Real Estate Finance and Economics 44(1-2): 90-115.

Jarrow R (1986).The relationship between arbitrage and first order stochastic dominance. Journal of Finance 41(4): 915-921. 
Joy OM and Porter RB (1974). Stochastic dominance and mutual fund performance. Journal of Financial and Quantitative Analysis 9(1): 24-31.

Kallberg JG, Liu CH and Greig DW (1996). The role of real estate in the portfolio allocation process. Real Estate Economics 24(3): 359-359.

Krainer J (2001). A theory of liquidity in residential real estate markets. Journal of Urban Economics 49(1): 32-53.

Leamer EE (2002). Bubble trouble? Your home has a P/E ratio too. UCLA Anderson Forecast June.

Leshno M and Levy H (2002). Preferred by "all"' and preferred by "most" decision makers: Almost stochastic dominance. Management Science 48(8): 1074-1085.

Levy H (1992). Stochastic dominance and expected utility: Survey and analysis. Management Science 38(4): 555-593.

Levy H and Levy M (2004). Prospect Theory and Mean-Variance Analysis, Review of Financial Studies 17(4), 1015-1041.

Levy H and Wiener Z (1998). Stochastic Dominance and Prospect Dominance with Subjective Weighting Functions. Journal of Risk and Uncertainty 16(2), 147-163.

Levy M and Levy H (2002). Prospect Theory: Much ado about nothing? Management Science 48(10): 1334-1349.

Levy H and Sarnat M (1970). Alternative efficiency criteria: An empirical analysis. Journal of Finance 25(5): 1153-1158.

Li CK and Wong WK (1999). Extension of Stochastic Dominance Theory to Random Variables. RAIRO Operations Research 33, 509-524.

Lin Z and Liu Y (2008). Real estate returns and risk with heterogeneous investors. Real Estate Economics 36(4): 753-776.

Linton O, Maasoumi E and Whang Y-J (2005). Consistent testing for stochastic dominance under general sampling schemes. Review of Economic Studies 72(3): 735-765. 
Markowitz HM (1952). The Utility of Wealth. Journal of Political Economy 60, 151-156.

McMillen DP (2008). Changes in the distribution of house prices over time: structural characteristics, neighborhood, or coefficients? Journal of Urban Economics 64(3): 573-589.

Paciorek A and Sinai T (2012). Does home owning smooth the variability of future housing consumption? Journal of Urban Economics 71(2): 244-257.

Porter RB (1973). An empirical comparison of stochastic dominance and mean-variance portfolio choice criteria. Journal of Financial and Quantitative Analysis 8(4): $587-608$.

Qiao Z, Clark E and Wong, WK (2014). Investors' preference towards risk: evidence from the Taiwan stock and stock index futures markets. Accounting \& Finance 54(1): 251-274.

Qiao Z and Wong, WK (2015). Which is a better investment choice in the Hong Kong residential property market: a big or small property? Applied Economics 47(16), $1670-1685$.

Sriboonchitta, S., Wong, W.K., Dhompongsa, S., and Nguyen, H.T., 2009. Stochastic Dominance and Applications to Finance, Risk and Economics. Chapman and Hall/CRC, Taylor and Francis Group.

Topel R and Rosen S (1988). Housing investment in the United States. Journal of Political Economy 96(4): 718-740.

Tsang,CK, Gao, JJ, Li, XL and Wong, WK (2012). Big house or small house, which one should we buy? Evidence from Hong Kong, Social Science Research Network Working Paper Series 2182403.

Turnbull GK, Dornbrow JD and Simans CF (2008). Big house, little house: Relative size and value. Real Estate Economics 34(3): 439-456.

Wong, WK (2007). Stochastic dominance and mean-variance measures of profit and loss for business planning and investment. European Journal of Operational 
Research 182(2), 829-843.

Wong WK and Chan R (2008). Markowitz and Prospect Stochastic Dominances. Annals

of Finance 4(1): 105-129.

Wong WK, Phoon KF and Lean HH (2008). Stochastic dominance analysis of Asian hedge funds. Pacific-Basin Finance Journal 16(3): 204-223.

Xiao, Q and Liu, Y (2010). The residential market of Hong Kong: rational or irrational? Applied Economics 42: 923-33.

Ziering B and McIntosh W (2000). Property size and risk: Why bigger is not always better. Journal of Property Management 5(2): 62-70.

Zimmer DM (2012). The role of copulas in the housing crisis. The Review of Economics and Statistics 94(2): 607-620. 
Table 1 Descriptive statistics of rental yield

\begin{tabular}{l|ccccc}
\hline \multirow{2}{*}{} & \multicolumn{5}{c}{ Class } \\
\cline { 2 - 6 } \multicolumn{1}{c}{$\mathrm{A}$} & $\mathrm{B}$ & $\mathrm{C}$ & $\mathrm{D}$ & $\mathrm{E}$ \\
\hline Mean (\%) & $\mathbf{0 . 4 1 2 \%}$ & $0.346 \%$ & $0.326 \%$ & $0.309 \%$ & $\mathbf{0 . 2 8 0 \%}$ \\
Std Dev (\%) & $\mathbf{0 . 0 8 3 \%}$ & $\mathbf{0 . 0 6 3 \%}$ & $0.074 \%$ & $0.079 \%$ & $0.080 \%$ \\
Maximum (\%) & $0.540 \%$ & $0.460 \%$ & $0.470 \%$ & $0.460 \%$ & $0.450 \%$ \\
Minimum (\%) & $0.260 \%$ & $0.230 \%$ & $0.220 \%$ & $0.200 \%$ & $0.180 \%$ \\
Skewness & -0.196 & -0.026 & 0.259 & 0.347 & 0.452 \\
Kurtosis & -1.038 & -1.014 & -1.137 & -1.145 & -1.129 \\
Jarque-Bera & $9.237^{* * *}$ & $7.733^{* * *}$ & $11.716^{* * *}$ & $13.452^{* * *}$ & $15.692^{* * *}$ \\
\hline
\end{tabular}

Note: Classes A and Bare the "most outstanding classes" in which Class A has the highest monthly mean yield (0.412\%); Class B has the smallest standard deviation $(0.063 \%)$; and Class $\mathrm{E}$ has the smallest monthly mean yield $(0.280 \%)$;Class A has the largest standard deviation $(0.083 \%)$. Results in bold are extreme values. Readers may refer to Section 3 for information on the different classes.

$*, * *, * * *$ denote significance at the $10 \%, 5 \%$, and $1 \%$ levels, respectively.

Table 2 Results of the Davidson-Duclos (DD) test of rental yield for risk averters

\begin{tabular}{l|cccccc}
\hline Sample & \multicolumn{2}{|c}{ FSD } & \multicolumn{2}{c}{ SSD } & \multicolumn{2}{c}{ TSD } \\
\hline & $\% T_{1}>0$ & $\% T_{1}<0$ & $\% T_{2}>0$ & $\% T_{2}<0$ & $\% T_{3}>0$ & $\% T_{3}<0$ \\
\hline Class A - Class B & 0 & 93 & 0 & 96 & 0 & 96 \\
Class A - Class C & 0 & 94 & 0 & 96 & 0 & 94 \\
Class A - Class D & 0 & 94 & 0 & 97 & 0 & 97 \\
Class A - Class E & 0 & 94 & 0 & 97 & 0 & 99 \\
Class B - Class C & 0 & 50 & 0 & 95 & 0 & 93 \\
Class B - Class D & 0 & 65 & 0 & 96 & 0 & 96 \\
Class B - Class E & 0 & 89 & 0 & 99 & 0 & 99 \\
Class C - Class D & 0 & 33 & 0 & 96 & 0 & 96 \\
Class C - Class E & 0 & 90 & 0 & 96 & 0 & 99 \\
Class D - Class E & 0 & 74 & 0 & 99 & 0 & 99 \\
\hline
\end{tabular}

Note: The DD test statistics are computed over a grid of 100 on monthly yields. The table reports the percentage of DD statistics that are significantly negative or positive at the $5 \%$ significance level, based on the simulated critical value recommended by Bai et al. (2011). $T_{j}$ is the Davidson and Duclos (DD) statistic for risk-averters with $j=1,2$, and 3 defined in equation (2)with $F$ being the first series and $G$ being the second series stated in the first column. 
Table 3 Pairwise comparison between rental yields by the Davidson-Duclos (DD) tests

\begin{tabular}{c|ccccc} 
Class & A & B & C & D & E \\
\hline A & & FSD & FSD & FSD & FSD \\
B & NS & & FSD & FSD & FSD \\
C & NS & NS & & FSD & FSD \\
D & NS & NS & NS & & FSD \\
E & NS & NS & NS & NS & \\
\hline
\end{tabular}

Notes: The results in this table are read based on row versus column. For example, the cell in row A and column B tells us that Class A stochastically dominates Class B at first-order SD, while the cell in row B and column A means that Class B does not stochastically dominate Class A.

*NS: no stochastic dominance, FSD: first-order stochastic dominance.

Table 4 Descriptive statistics of total yield

\begin{tabular}{l|ccccc}
\hline & $\mathrm{A}$ & $\mathrm{B}$ & $\mathrm{C}$ & $\mathrm{D}$ & $\mathrm{E}$ \\
\cline { 2 - 6 } \multicolumn{1}{c}{} & $\mathrm{A}$ & $\mathbf{\mathrm { C }}$ & $\mathbf{0}$ & \\
\hline Mean (\%) & $\mathbf{0 . 9 5 2 \%}$ & $0.815 \%$ & $\mathbf{0 . 8 1 3 \%}$ & $0.837 \%$ & $0.843 \%$ \\
Std Dev (\%) & $\mathbf{2 . 2 9 4 \%}$ & $2.299 \%$ & $2.620 \%$ & $2.637 \%$ & $\mathbf{3 . 0 6 3 \%}$ \\
Maximum (\%) & $7.730 \%$ & $7.220 \%$ & $9.520 \%$ & $10.760 \%$ & $9.600 \%$ \\
Minimum (\%) & $-7.030 \%$ & $-7.860 \%$ & $-8.780 \%$ & $-9.560 \%$ & $-9.230 \%$ \\
Skewness & -0.205 & -0.309 & 0.047 & -0.028 & -0.129 \\
Kurtosis & 0.717 & 1.158 & 2.073 & 2.504 & 0.965 \\
Jarque-Bera & $5.116^{*}$ & $12.922^{* * *}$ & $32.300^{* * *}$ & $47.055^{* * *}$ & $7.482^{* *}$ \\
\hline
\end{tabular}

Note: Classes A is the "most outstanding class" in which Class A has the highest monthly mean yield (0.952\%) and the smallest standard deviation (2.294\%); and Class Chas the smallest monthly mean yield $(0.813 \%)$; Class E has the largest standard deviation (3.063\%). Results in bold are extreme values. Readers may refer to Section 3 for information on the different classes.

$*, * *, * * *$ denote significance at the $10 \%, 5 \%$, and $1 \%$ levels, respectively. 
Table 5 Results of the Davidson-Duclos (DD) test of total yield for risk averters

\begin{tabular}{l|cccccc}
\hline Sample & \multicolumn{3}{|c}{ FSD } & \multicolumn{2}{c}{ SSD } & \multicolumn{2}{c}{ TSD } \\
\hline & $\% T_{1}>0$ & $\% T_{1}<0$ & $\% T_{2}>0$ & $\% T_{2}<0$ & $\% T_{3}>0$ & $\% T_{3}<0$ \\
\hline Class A - Class B & 0 & 0 & 0 & 0 & 0 & 0 \\
Class A - Class C & 0 & 0 & 0 & 0 & 0 & 16 \\
Class A - Class D & 0 & 0 & 0 & 0 & 0 & 1 \\
Class A - Class E & 0 & 0 & 0 & 30 & 0 & 48 \\
Class B - Class C & 0 & 0 & 0 & 0 & 0 & 0 \\
Class B - Class D & 0 & 0 & 0 & 0 & 0 & 0 \\
Class B - Class E & 1 & 1 & 0 & 4 & 0 & 40 \\
Class C - Class D & 0 & 0 & 0 & 0 & 0 & 0 \\
Class C - Class E & 0 & 0 & 0 & 0 & 0 & 0 \\
Class D - Class E & 0 & 0 & 0 & 0 & 0 & 0 \\
\hline
\end{tabular}

Note: The DD test statistics are computed over a grid of 100 on monthly yields. The table reports the percentage of DD statistics that are significantly negative or positive at the $5 \%$ significance level, based on the simulated critical value recommended by Bai et al. (2011). $T_{j}$ is the Davidson and Duclos (DD) statistic for risk-averters with $j=1,2$, and 3 defined in equation (2) with $F$ being the first series and $G$ being the second series stated in the first column.

Table 6 Pairwise comparison between total yields by the Davidson-Duclos (DD) tests

\begin{tabular}{c|ccccc} 
Class & A & B & C & D & E \\
\hline A & & NS & TSD & TSD\# & SSD \\
B & NS & & NS & NS & SSD \\
C & NS & NS & & NS & NS \\
D & NS & NS & NS & & NS \\
E & NS & NS & NS & NS & \\
\hline
\end{tabular}

Notes: The results in this table are read based on row versus column. For example, the cell in row A and column B tells us that Class A stochastically dominates Class B at first-order SD, while the cell in row B and column A means that Class B does not stochastically dominate Class A.

*NS: no stochastic dominance, FSD, SSD, TSD: first-order, second-order, third-order stochastic dominance. \# indicates it is marginally SD. 
Figure 1 Time-series plot of rental yields from all classes

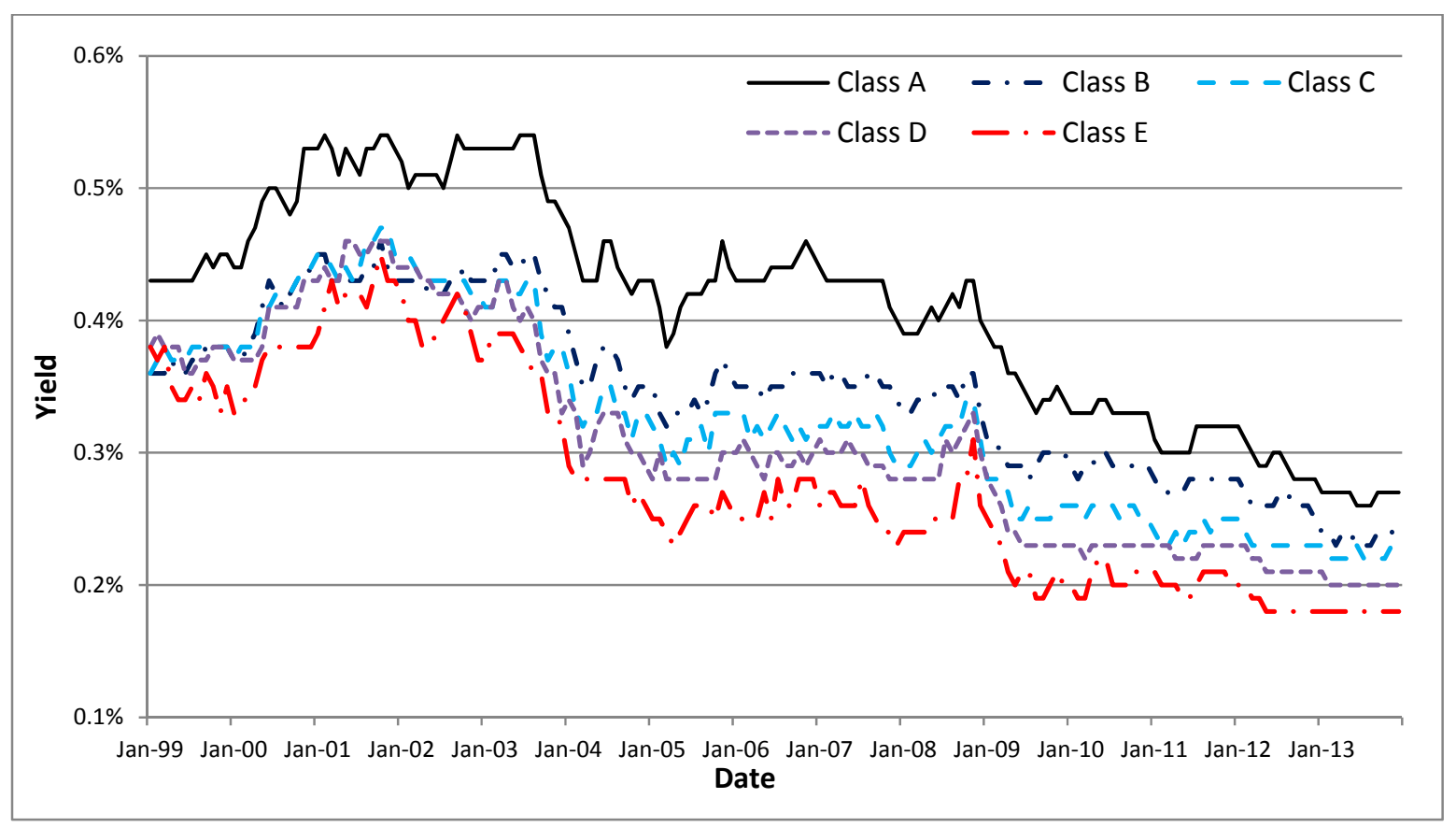

Figure 2 Density plot of rental yields from all classes

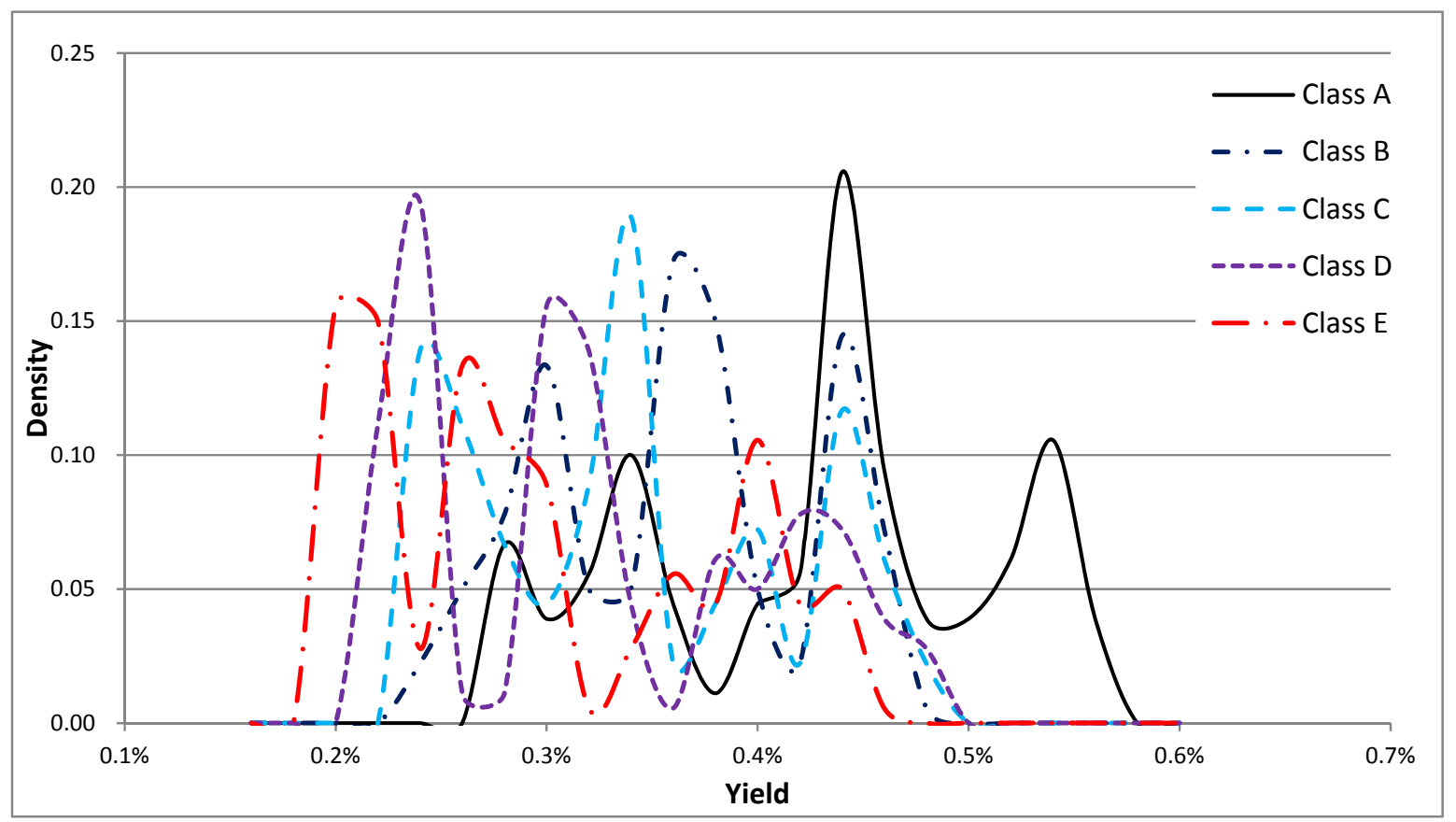


Figure 3 Cumulative distribution plot of rental yields from all classes

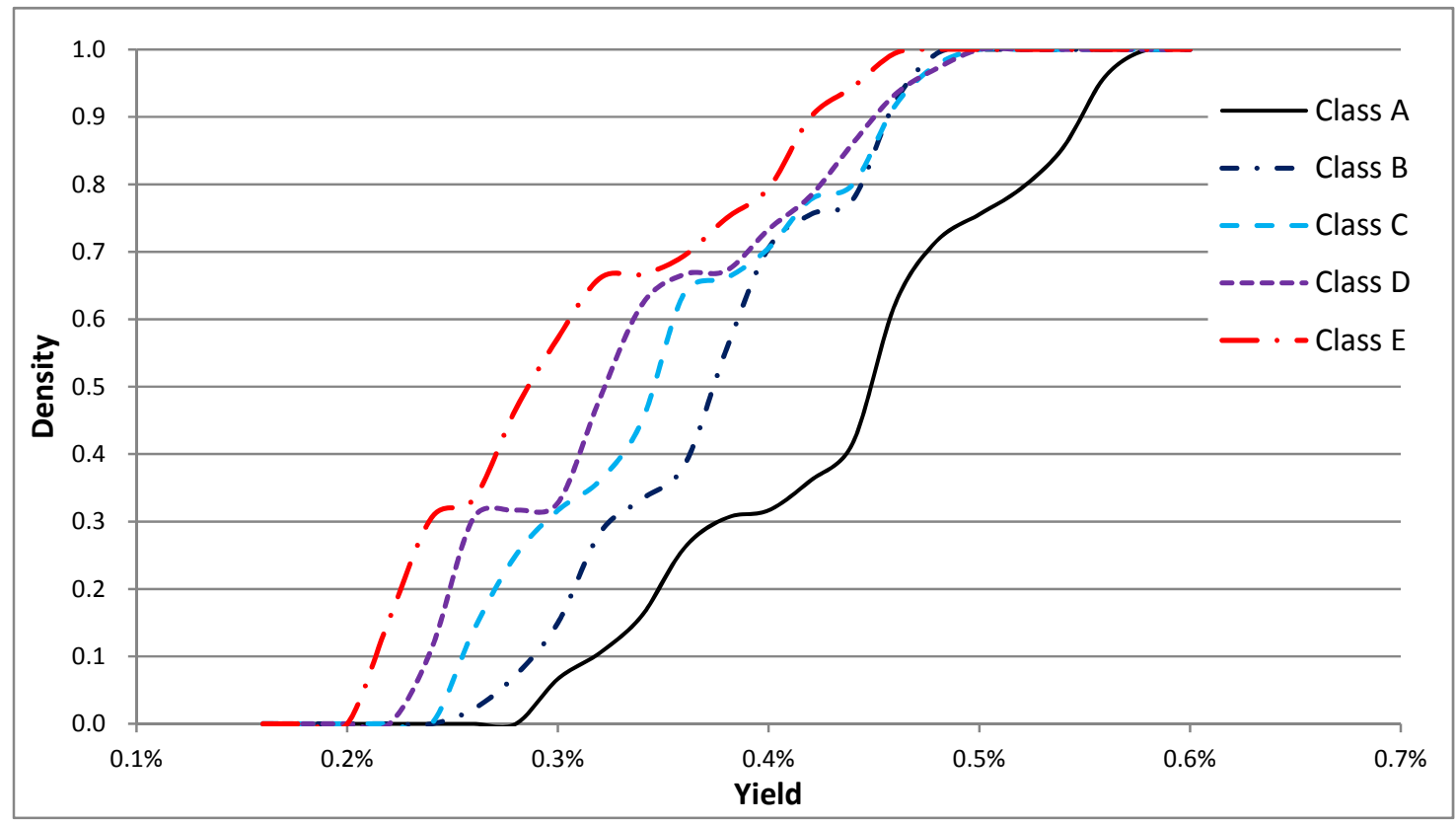

Figure 4 SD test statistics and the distribution functions of rental yields from classes A and $\mathrm{E}$

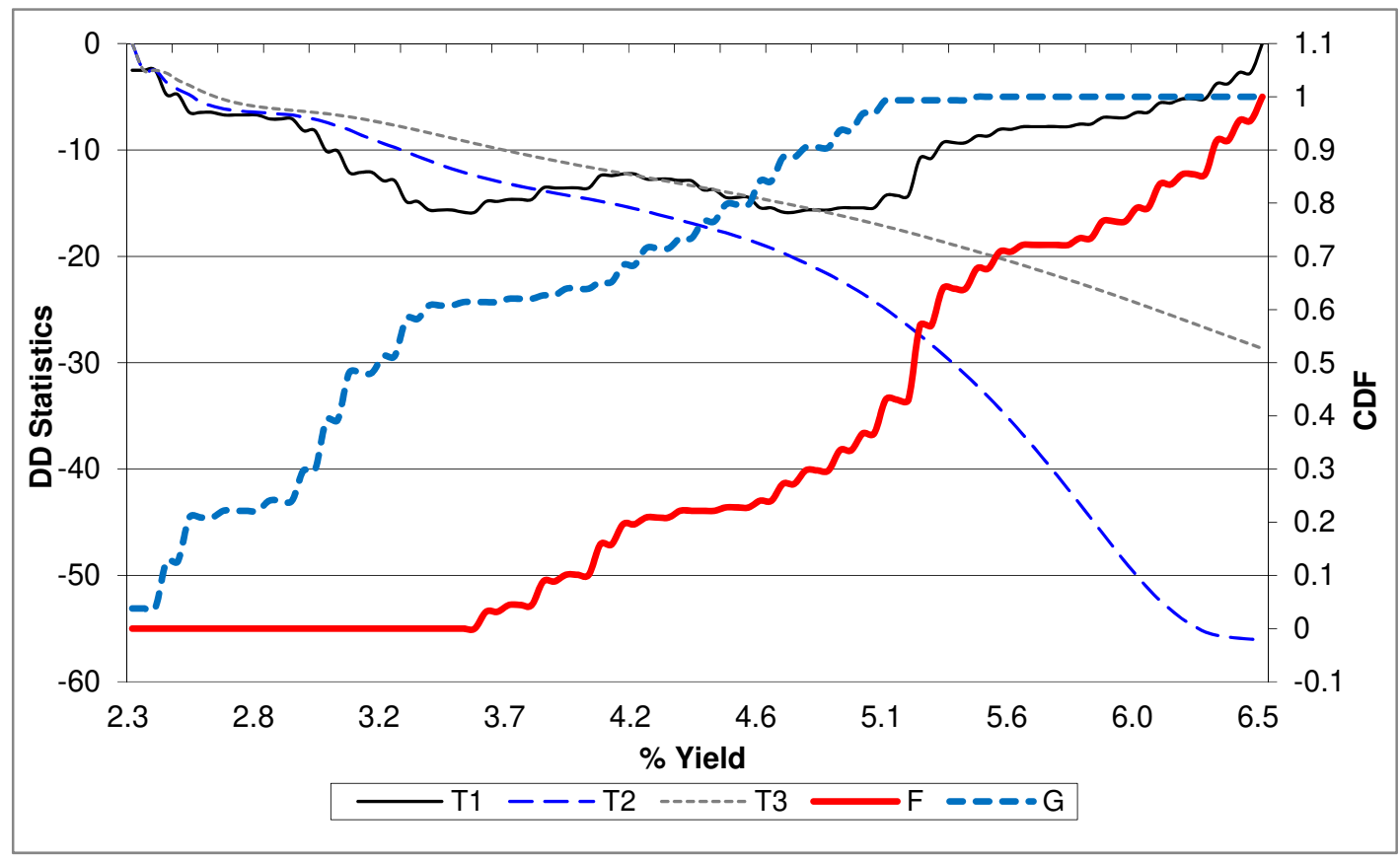

Note: $T_{j}$ is the test statistic defined in (2) for $j=1 ; 2$, and 3 with $F=$ yield from Class $A$ and $G=$ yield from Class $E$. 
Figure 5 Time-series plot of total yields from all classes

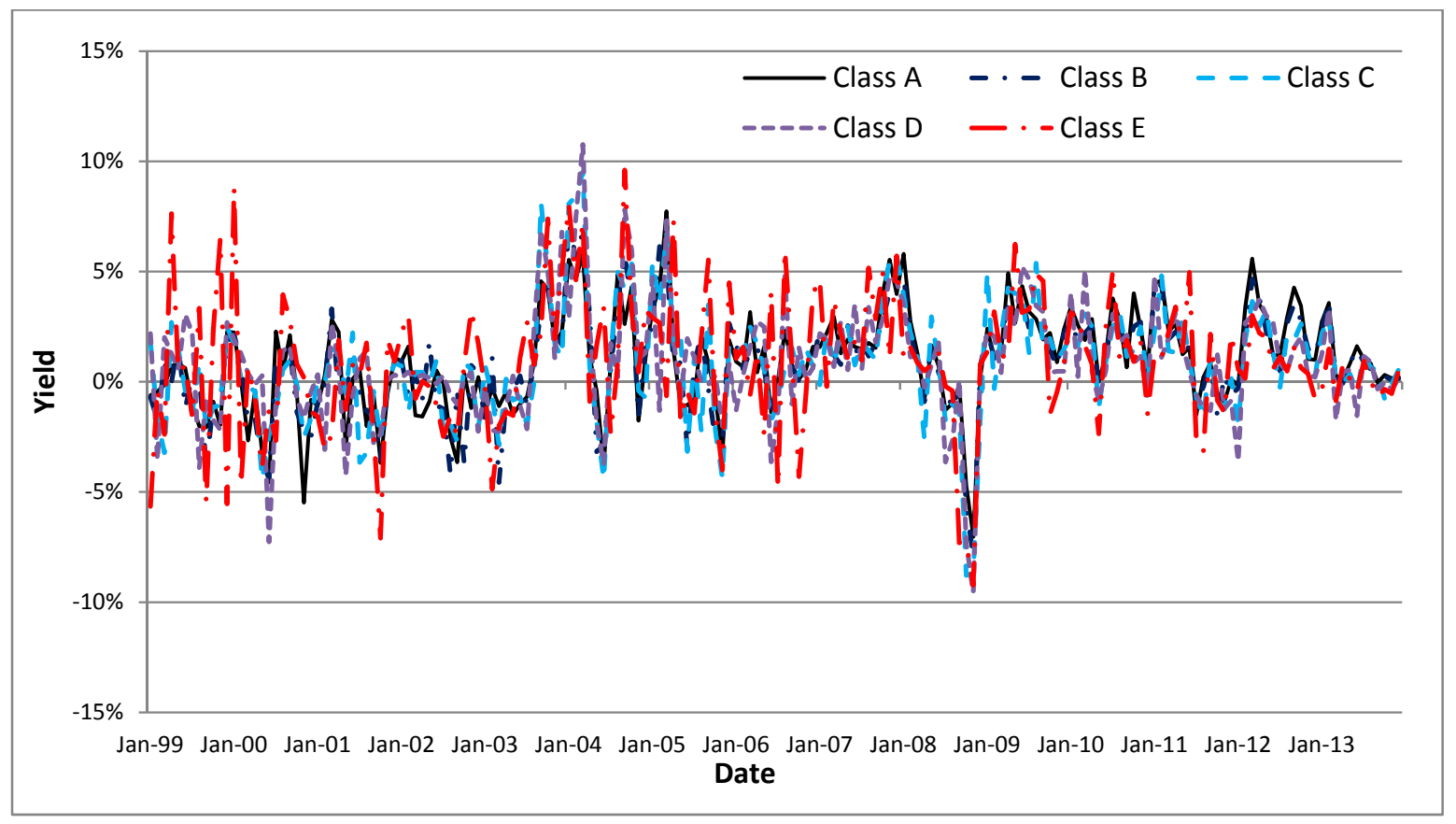

Figure 6 Density plot of total yields from all classes

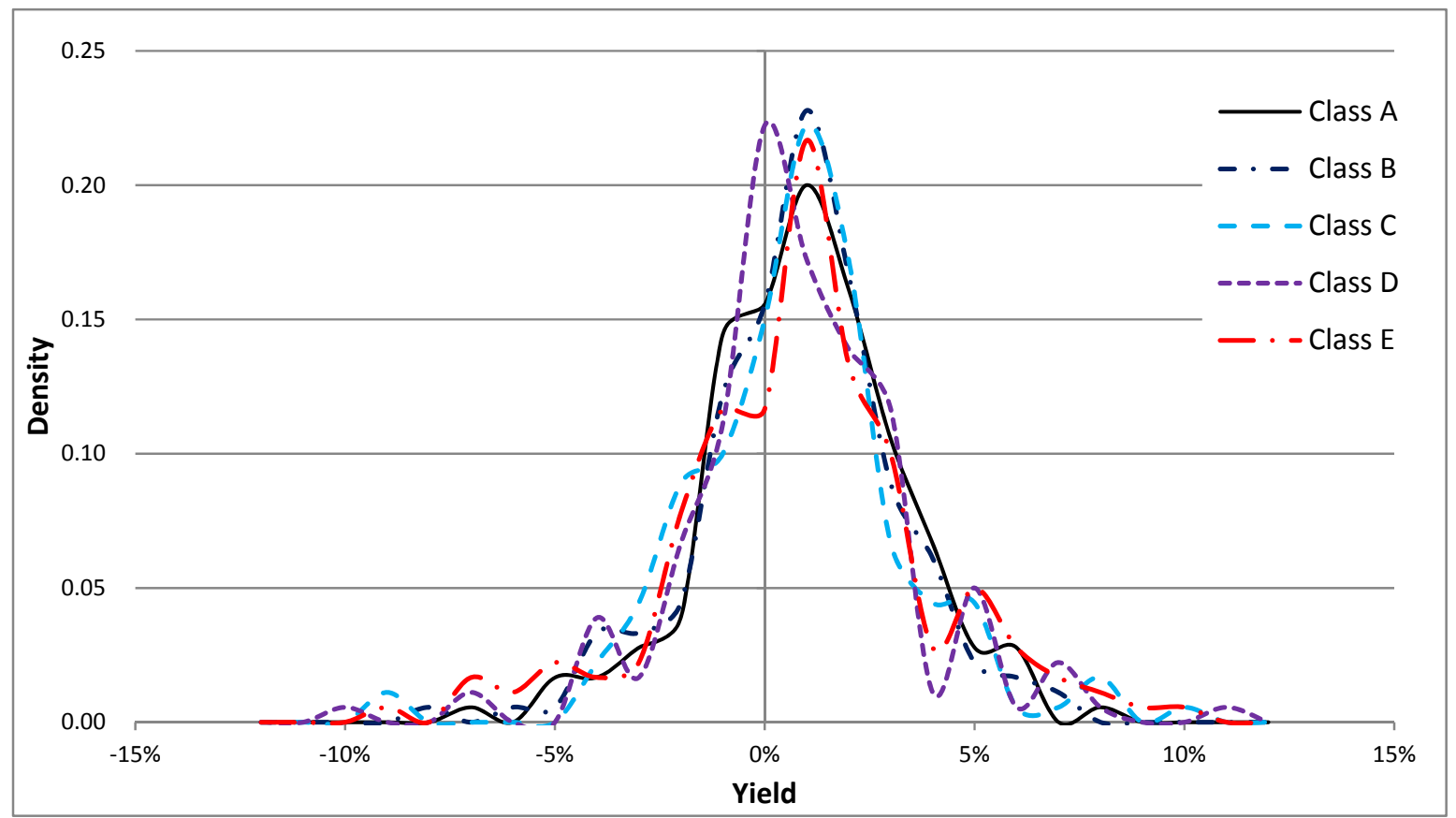


Figure 7 Cumulative distribution plot of total yield from all classes

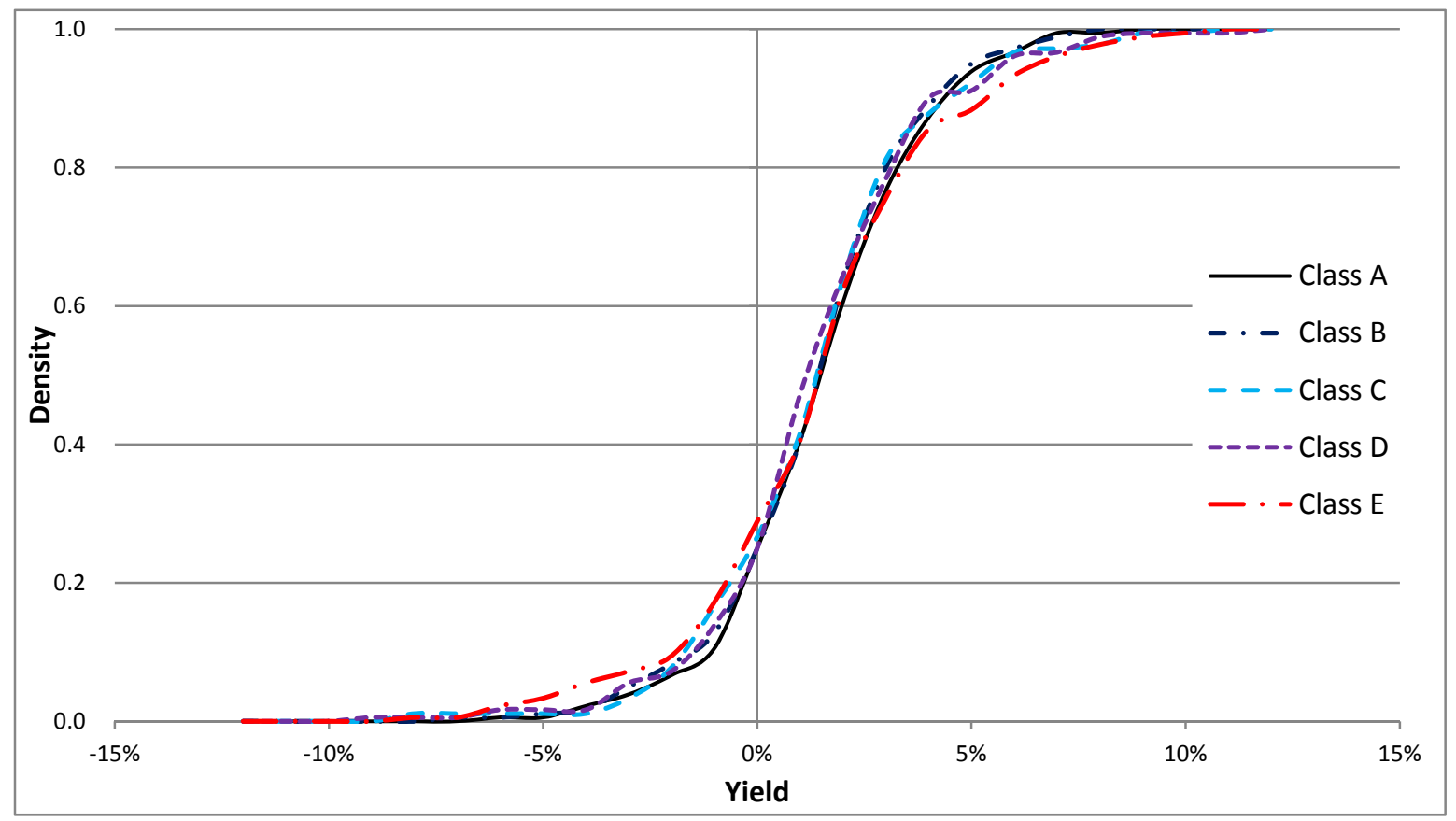

